\title{
A Compact Size 4-19.1 GHz Heart Shape UWB Antenna with Triangular Patches
}

\author{
Gokmen Isik $^{1}$ and Serkan Topaloglu ${ }^{2}$ \\ ${ }^{1}$ Electrical-Electronics Engineering Department, Faculty of Engineering, Yeditepe University, 34755 Istanbul, Turkey \\ ${ }^{2}$ TRON Elektronik Sist. San. ve Tic. A.S., 34776 Istanbul, Turkey \\ Correspondence should be addressed to Serkan Topaloglu; serkantopaloglu77@gmail.com
}

Received 31 May 2013; Revised 19 November 2013; Accepted 20 November 2013

Academic Editor: Alistair P. Duffy

Copyright (c) 2013 G. Isik and S. Topaloglu. This is an open access article distributed under the Creative Commons Attribution License, which permits unrestricted use, distribution, and reproduction in any medium, provided the original work is properly cited.

\begin{abstract}
An ultrawideband antenna is designed, simulated, and realized. To overcome the narrow bandwidth characteristics of basic patch antennas, the structure of the radiation pattern is optimized by the aid of elliptical and rectangular patches. Also triangular patches are applied to the antenna edge in order to enhance the VSWR and gain properties. A typical VSWR of 1.5 (less than 2 in the whole frequency range) and a typical gain of $2 \mathrm{dBi}$ (mainly above $1 \mathrm{dBi}$ in the whole frequency range) are observed. The simulations present that the designed antenna has a bandwidth ratio of $\sim 5: 1$ within the frequency range of $4-19.1 \mathrm{GHz}$ with compact dimensions of $25 \times 26 \mathrm{~mm}^{2}$. It is fabricated on a $0.5 \mathrm{~mm}$ thick, RO3035 substrate. The input impedance, gain, and radiation characteristics of the antenna are also presented. With these properties, it is verified that, with its novel shape, the proposed antenna can be used for various UWB applications.
\end{abstract}

\section{Introduction}

In last decades, the ultrawideband (UWB) technology is developed widely and rapidly. There are many applications employing UWB such as sensor networks [1], location tracking, and biomedical imaging [2]. UWB technology has also become very popular in high speed short range communication systems. Since antenna has a major effect on the performance of these systems, design of the compact antennas has become more important and critical. As a result of these, for broadband and ultrawideband (UWB) applications, patch antennas are an attractive candidate due to their light weight, low cost, wide bandwidth, compact size, and ease of fabrication [3-10].

Here it should be also noted that, since the transmission power in UWB is pretty low, the loss becomes an important issue. Moreover, power loss due to the dielectric and conductor losses needs to be minimized with the selection of a proper substrate.

In the work of Ojaroudi et al. [3], an ultrawideband monopole antenna with inverted T-shaped notch in the ground plane, operating from $3.12 \mathrm{GHz}$ to $12.73 \mathrm{GHz}$, is presented with a compact size of $12 \times 18 \mathrm{~mm}^{2}$. A monopole antenna with ladder-shaped resonant structures is also presented. This antenna has a dimension of $22 \times 22 \mathrm{~mm}^{2}$ with a bandwidth of $19.3 \mathrm{GHz}$ [4]. Liu and Yang [5] presented a hook-shaped UWB antenna operating from $3 \mathrm{GHz}$ to $10.7 \mathrm{GHz}$ with a dimension of $10 \times 10 \mathrm{~mm}^{2}$. A microstrip-fed, hexagonal wide slot antenna having $30 \times 30 \mathrm{~mm}^{2}$ area exhibited UWB performance from $2.9 \mathrm{GHz}$ to $18 \mathrm{GHz}$ [6]. A printed circular ring antenna operating from $2.54 \mathrm{GHz}$ to $12.08 \mathrm{GHz}$ is also presented in the literature [7]. In the work of Oudaya Coumar et al. [8], planar monopole antenna operating between $1.8 \mathrm{GHz}$ and $10.6 \mathrm{GHz}$ is studied with an area of $25 \times 30 \mathrm{~mm}^{2}$. Symmetrical triangle-shaped [9] and tapered-shaped slot antennas [10] with areas of $12 \times$ $38 \mathrm{~mm}^{2}$ and $22 \times 24 \mathrm{~mm}^{2}$ presented operation frequencies from $2.77 \mathrm{GHz}$ to $10.64 \mathrm{GHz}$ and from $3 \mathrm{GHz}$ to $11.2 \mathrm{GHz}$, respectively.

To overcome the narrow bandwidth property of patch antennas, different techniques have been investigated and applied to cover the entire UWB frequency range [11-14]. 


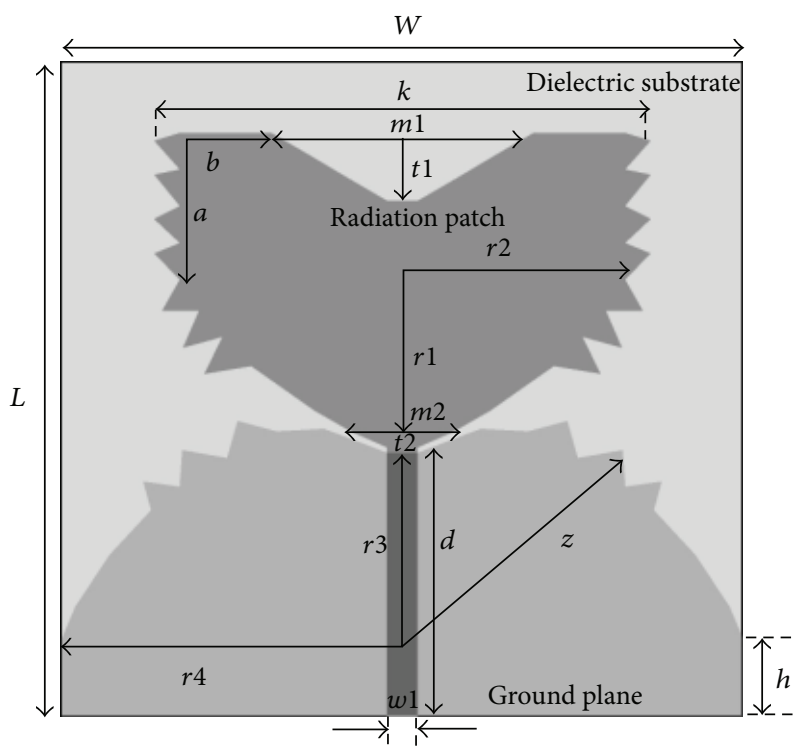

FIGURE 1: Geometry of the proposed UWB antenna. $(w 1=1.16 \mathrm{~mm}$, $m 1=10 \mathrm{~mm}, m 2=6 \mathrm{~mm}, t 1=0.6 \mathrm{~mm}, t 2=2.1 \mathrm{~mm}, z=13 \mathrm{~mm}$, $h=3 \mathrm{~mm}, a=5.6 \mathrm{~mm}, b=3.5 \mathrm{~mm}, r 1=6.4 \mathrm{~mm}, r 2=8.5 \mathrm{~mm}$, $r 3=12 \mathrm{~mm}, r 4=12.5 \mathrm{~mm}, k=19 \mathrm{~mm}, d=11.9 \mathrm{~mm}, W=25 \mathrm{~mm}$, and $L=26 \mathrm{~mm}$.)

In this work, a "heart shape" slot antenna with enhanced impedance bandwidth has been designed and fabricated. The objective of the work is to enlarge the bandwidth of the antenna while reducing the antenna dimensions to make it appropriate for portable systems and electronic devices. With the help of triangular patch and small segment of arc (as shown in Figure 1 as " $m 2$ ") at the middle of the ground plane [15-20], wide input impedance matching is achieved over the entire $4-19.1 \mathrm{GHz}$ band. The simulation and measurement for the return loss and VSWR indicate that the proposed structure exhibits an ultrawideband impedance matching and offers an antenna gain greater than $1 \mathrm{dBi}$.

\section{Antenna Configuration}

UWB operation is basically defined as the operating frequencies of $3.1 \mathrm{GHz}$ to $10.6 \mathrm{GHz}$ and as $6 \mathrm{GHz}$ to $8.5 \mathrm{Ghz}$ with the definition of U.S. FCC [21] and European regulations (2007/131/EC) [22], respectively. On the other hand, a general definition is also given with the equation

$$
\frac{2\left(f_{H}-f_{L}\right)}{\left(f_{H}+f_{L}\right)}>0.2
$$

where $f_{H}$ and $f_{L}$ are the upper and lower frequencies, respectively [23].

The basic structure of a heart shape antenna consists of a radiation element and modified ground plane as given in Figure 1. The radiating element of the presented antenna is designed with rectangular and elliptical patch. Rectangular and elliptical shapes are well known antenna types, and they have UWB characteristics with a wide frequency range. "V" slot notch is one of the techniques which augments the gain

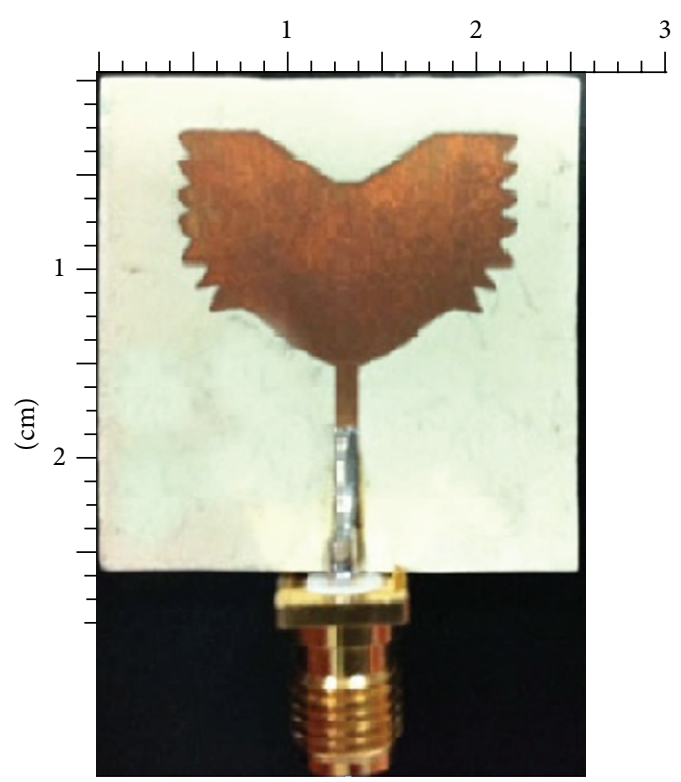

(a)

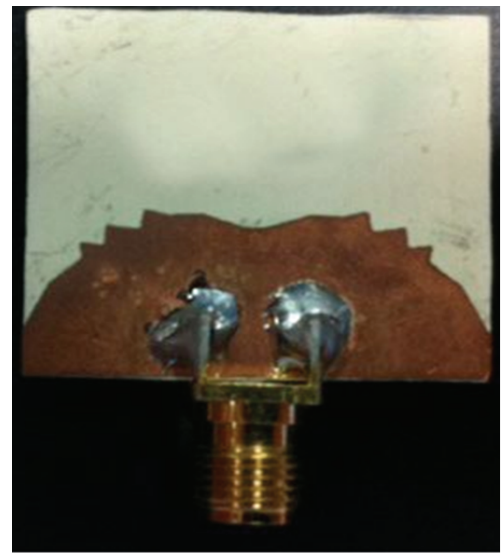

(b)

FIGURE 2: Fabricated prototype (radiating patch (a), ground plane (b)).

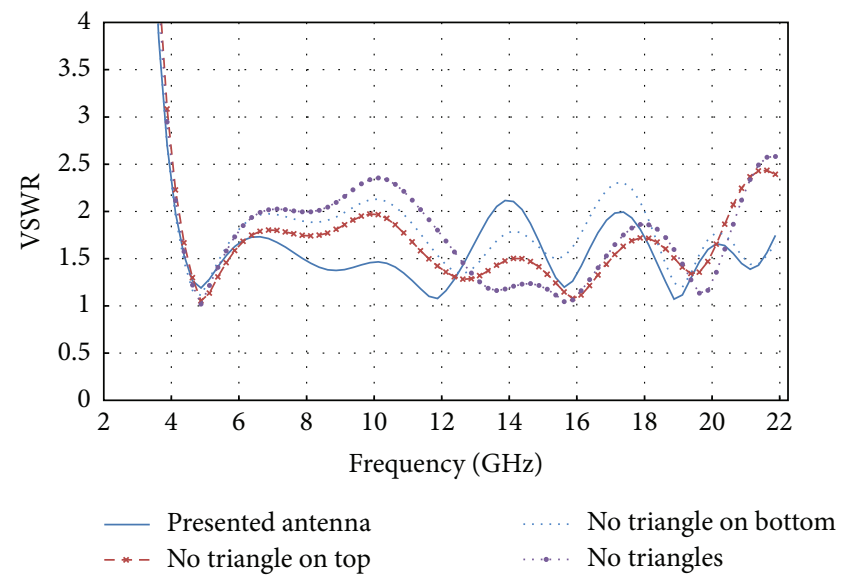

Figure 3: Comparison of VSWR for w/out triangular patches. 


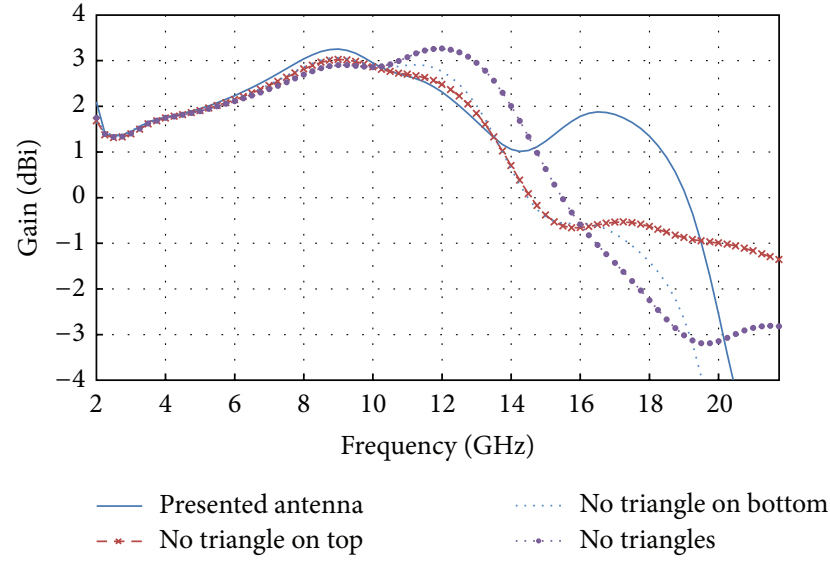

FIGURE 4: Comparison of gain for w/out triangular patches.

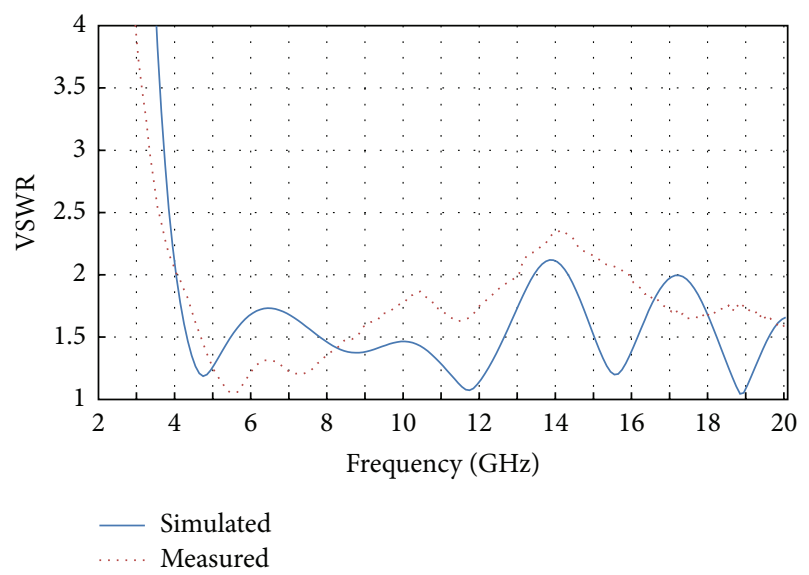

Figure 5: Comparison of simulated and measured VSWR.

and improves the impedance matching of the antenna. On the other hand, triangular-shaped patches are also used at the edge of rectangular patch in order to improve the impedance matching. When we consider the whole frequency range of the presented antenna, more than $100 \% \mathrm{BW}$ improvement is achieved in comparison to the UWB frequency range defined by FCC [17].

The ground plane used here is also similar to the radiating patch and it also consists of rectangular and elliptical patches. The gain and bandwidth of the antenna are improved by adding a small segment of arc at the middle of the ground plane as also applied in the work of Liu et al. [15]. Modified ground plane of the heart shape UWB antenna is shown in Figure 2. The dimension and the alignment of the ground plane and radiation element are also considered. The proposed antenna has compact dimension of $25 \times 26 \mathrm{~mm}^{2}$ which is printed on RO 3035 substrate from Rogers Corp. having $0.5 \mathrm{~mm}$ thickness and relative dielectric constant of 3.50. Since the dielectric substrate thickness is $0.5 \mathrm{~mm}$, antenna is flexible. Therefore, it may be also suitable for applications where flexibility is necessary, for example, wearable electronics.

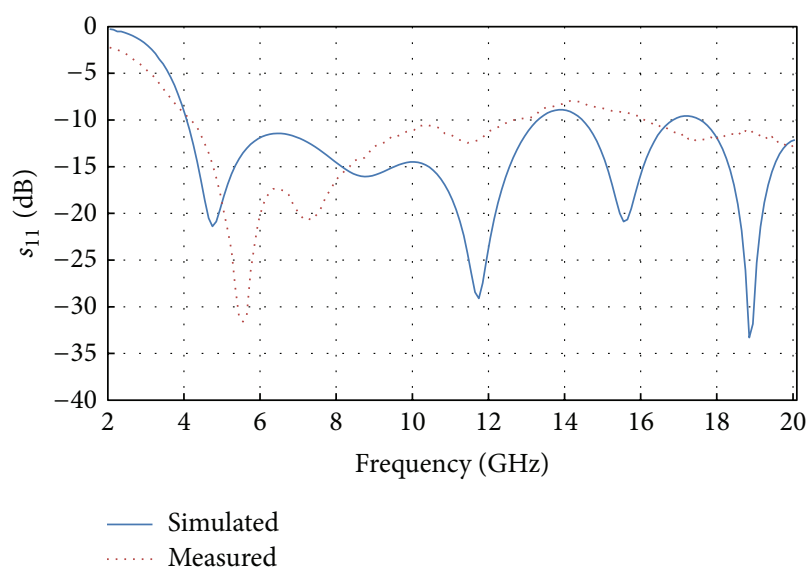

Figure 6: Comparison of simulated and measured return loss.

TABLE 1: Comparison of the proposed antenna with the recently published selected antennas.

\begin{tabular}{lccc}
\hline Work & Bandwidth $(\mathrm{GHz})$ & Size $(\mathrm{mm} \times \mathrm{mm})$ & Gain $(\mathrm{dBi})$ \\
\hline$[3]$ & $3.12-12.73$ & $12 \times 18$ & - \\
{$[4]$} & $2.7-20$ & $22 \times 22$ & - \\
{$[5]$} & $3-10.7$ & $10 \times 10$ & $\sim 1$ \\
{$[6]$} & $2.9-18$ & $30 \times 30$ & $\sim 3$ \\
{$[7]$} & $2.54-21.08$ & $39 \times 40$ & $\sim 0$ \\
{$[8]$} & $1.8-10.6$ & $25 \times 30$ & - \\
{$[9]$} & $2.77-10.64$ & $12 \times 38$ & $\sim 1$ \\
{$[10]$} & $3-11.2$ & $22 \times 24$ & $\sim 2$ \\
This work & $4-19.1$ & $25 \times 26$ & $\sim 1$ \\
\hline
\end{tabular}

\section{Results and Discussion}

In order to analyze the impact of the triangular patches on radiation element and ground plane, a serial of simulations are performed. It is clear from Figures 3 and 4 that triangles on the radiating element (on top) and the ground plane (on bottom) influence the antenna performance in terms of VSWR and gain. A better performance is achieved when triangles are applied to both sides. Briefly, the designed antenna presents VSWR below 2 and gain above $1 \mathrm{dBi}$ from $4 \mathrm{GHz}$ and up to 19.1 GHz.

For the measurement and the characterization of the antenna performance, a vector network analyzer from Agilent is used. The simulated and measured VSWR and return loss of the antenna are given in Figures 5 and 6 . These results illustrate impedance matching bandwidth between $4 \mathrm{GHz}$ and $19.1 \mathrm{GHz}$ range. As given in Figures 5 and 6, measurement result is roughly similar to the simulation results. The slight discrepancy is due to not only the effect of the SMAs used but also the tolerances during fabrication. The VSWR is measured to be below 2 (partially the measured VSWR is 2.3 close to the $14 \mathrm{GHz}$ ), whereas the gain is achieved above $1 \mathrm{dBi}$, typically. 


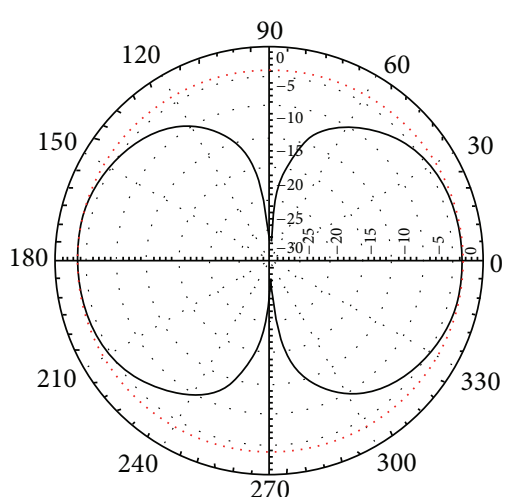

(a)

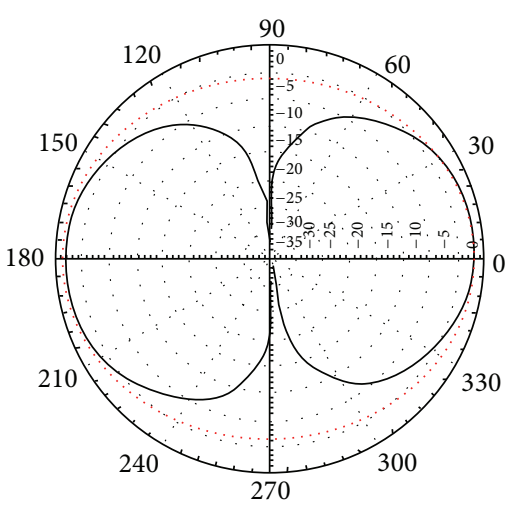

(d)

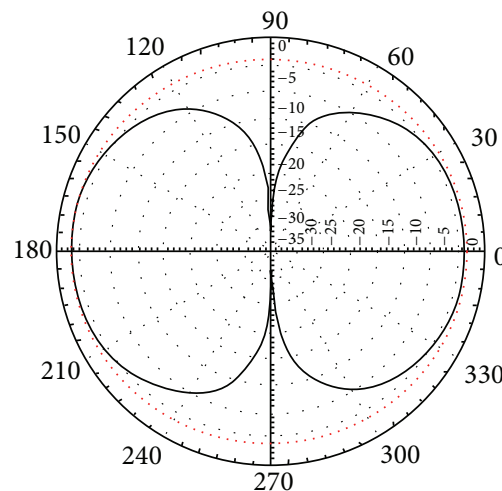

(b)

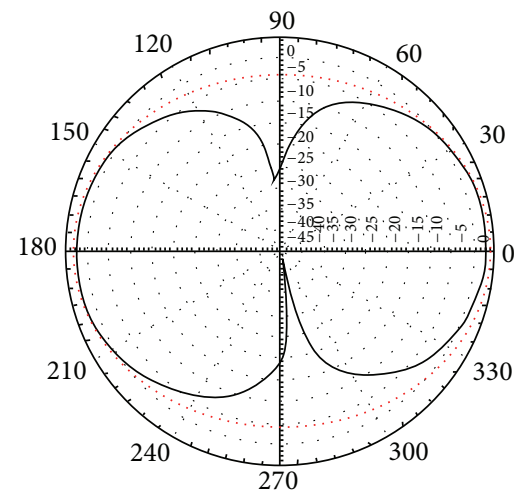

(e)

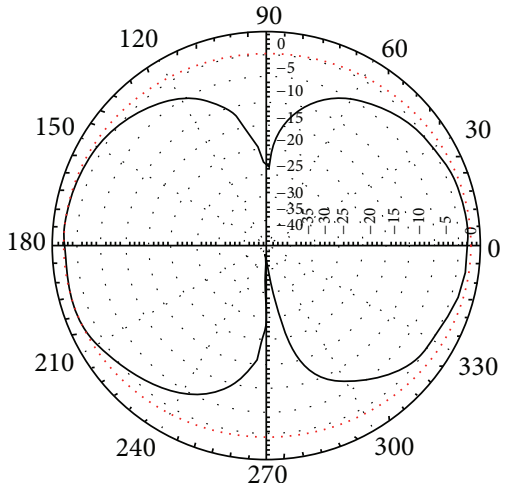

(c)

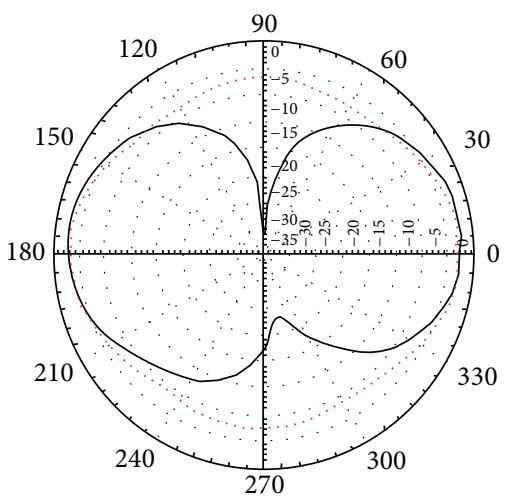

(f)

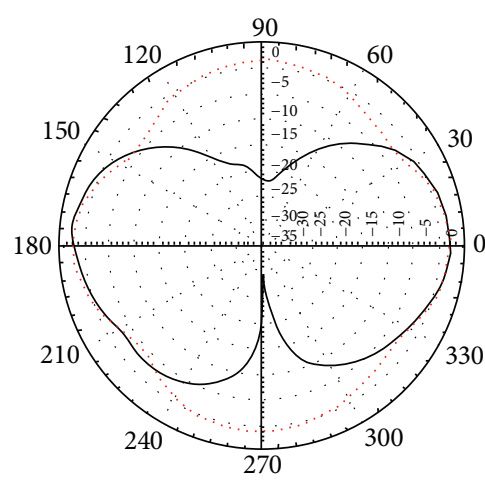

(g)

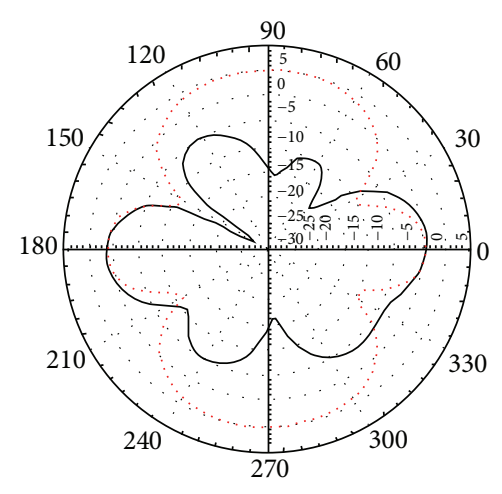

(h)

FIGURE 7: Normalized simulated radiation patterns of the antenna at (a) $3 \mathrm{GHz}$, (b) $4.5 \mathrm{GHz}$, (c) $6 \mathrm{GHz}$, (d) $7.5 \mathrm{GHz}$, (e) $9 \mathrm{GHz}$, (f) $10.5 \mathrm{GHz}$, (g) $12 \mathrm{GHz}$, and (h) $14 \mathrm{GHz}$.

The presented antenna in this paper is compared with the recently published antennas in Table 1 in terms of mainly bandwidth and size and also gain and the radiation pattern.

The proposed antenna in this work exhibits a pretty high bandwidth with its comparable size. It presents a moderate gain with a uniform the radiation pattern.

The simulated and measured radiation patterns in the $X-$ $Z$ and $Y-Z$ planes, for frequencies $3,4.5,6,7.5,9,10.5,12$, and $14 \mathrm{GHz}$, are presented in Figures 7 and 8, respectively.

These radiation patterns show a reasonably good agreement between simulations and measurements.

\section{Conclusion}

In this paper, a novel ultrawideband antenna named by us as heart shape antenna was designed, simulated, fabricated, and characterized. The structure of the radiation part is designed with elliptical and rectangular patches. Also triangular patches used at the edge of the antenna are analyzed to enhance the VSWR and gain of the antenna. In addition, modified ground of the presented antenna also consists of elliptical patches with a small segment of arc at the middle of the ground. With the help of the triangular patch on the modified ground, enhanced gain and impedance matching 


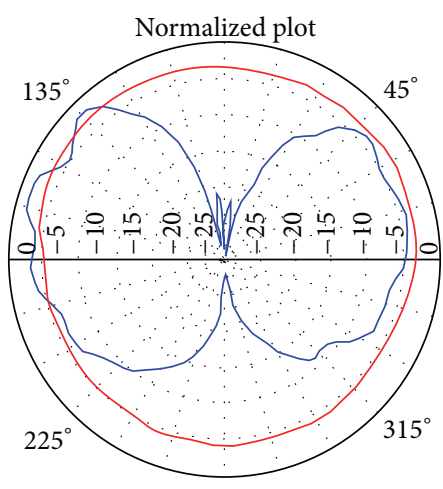

(a)

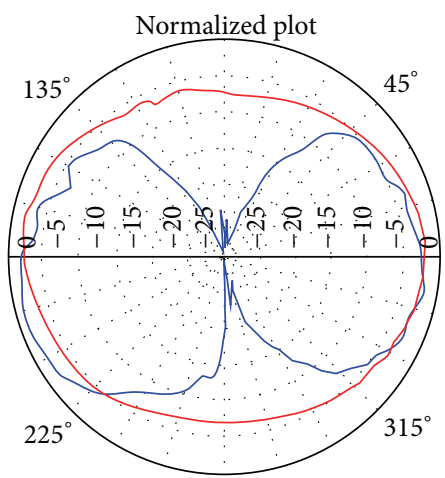

(d)

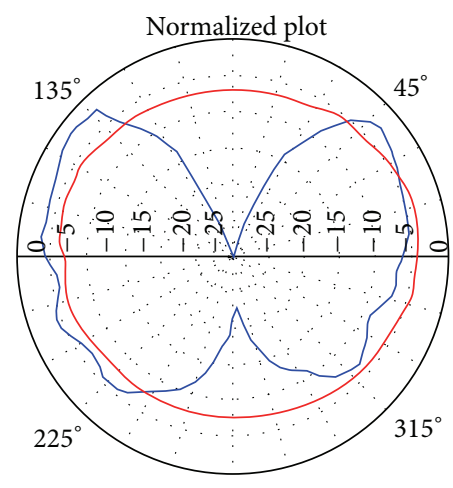

(b)

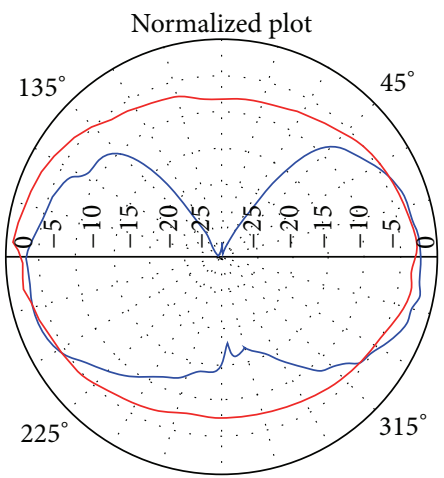

(e)

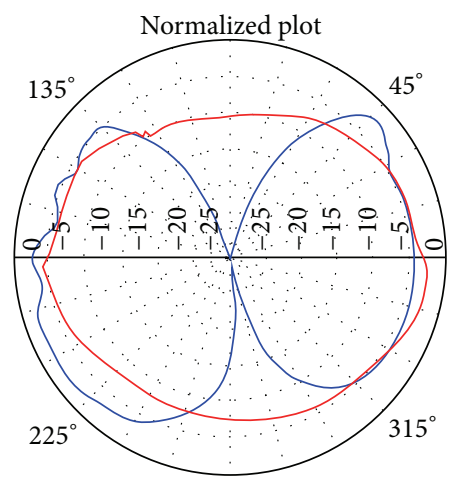

(c)

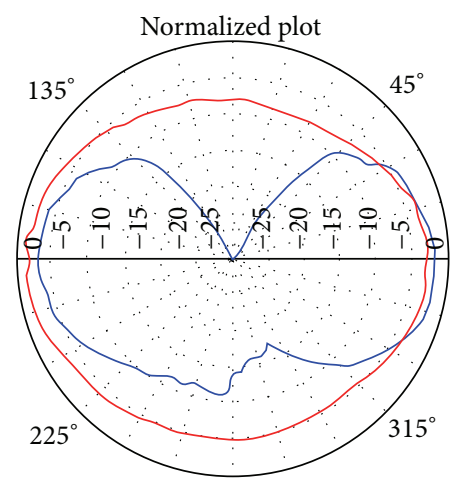

(f)

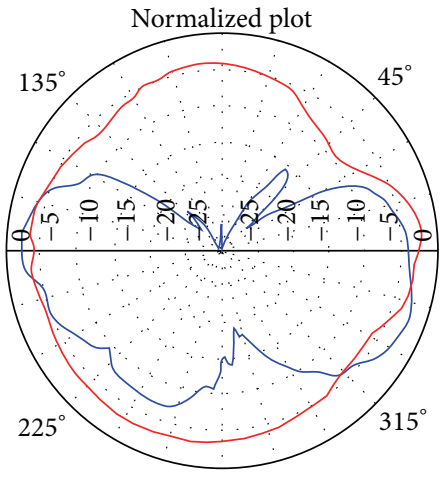

(g)

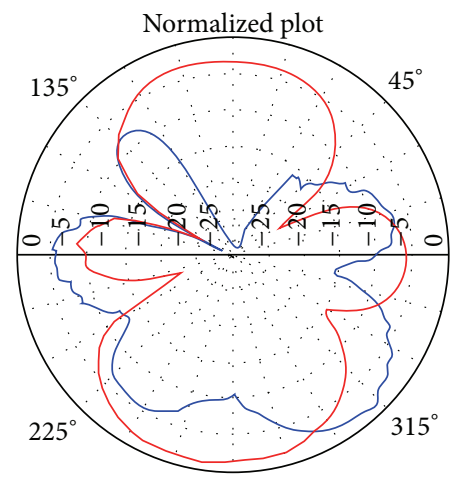

(h)

FIGURE 8: Normalized measured radiation patterns of the antenna at (a) $3 \mathrm{GHz}$, (b) $4.5 \mathrm{GHz}$, (c) $6 \mathrm{GHz}$, (d) $7.5 \mathrm{GHz}$, (e) $9 \mathrm{GHz}$, (f) $10.5 \mathrm{GHz}$, (g) $12 \mathrm{GHz}$, and (h) $14 \mathrm{GHz}$.

characteristics are achieved. Numerical simulation shows that the antenna has a bandwidth ratio of $5: 1$ within the frequency range of $4 \mathrm{GHz}-19.1 \mathrm{GHz}$ with a $25 \times 26 \mathrm{~mm}^{2}$ heart shape UWB antenna.

Briefly, a novel-shaped, flexible UWB antenna providing a VSWR less than 2 and gain of more than $1 \mathrm{dBi}$ is achieved and fabricated with a compact size of $25 \times 26 \mathrm{~mm}^{2}$ which makes it attractive for mobile systems.

\section{Acknowledgments}

The authors would like to thank Scientific and Technological Research Council of Turkey (TUBITAK), Center of Research for Advanced Technologies of Informatics and Security (BİLGEM), Electromagnetics and Antenna Systems (EAS) Department-Antenna Design and Research Center, and Spherical Near Field Measurement Laboratory for providing measurement support.

\section{References}

[1] J. R. Verbiest and G. A. E. Vandenbosch, "A novel small-size printed tapered monopole antenna for UWB WBAN," IEEE Antennas and Wireless Propagation Letters, vol. 5, no. 1, pp. 377379, 2006.

[2] H. Deng, X. He, B. Yao, and Y. Zhou, "A compact square-ring printed monopole ultra wideband antenna," in Proceedings of 
the International Conference on Microwave and Millimeter Wave Technology (ICMMT '08), pp. 1644-1646, Nanjing, China, April 2008.

[3] M. Ojaroudi, C. Ghobadi, and J. Nourinia, "Small square monopole antenna with inverted T-shaped notch in the ground plane for UWB application," IEEE Antennas and Wireless Propagation Letters, vol. 8, pp. 728-731, 2009.

[4] R. A. Sadeghzadeh-Sheikhan, M. Naser-Moghadasi, E. Ebadifallah, H. Rousta, M. Katouli, and B. S. Virdee, "Planar monopole antenna employing back-plane ladder-shaped resonant structure for ultra-wideband performance," IET Microwaves, Antennas and Propagation, vol. 4, no. 9, pp. 1327-1335, 2010.

[5] H.-W. Liu and C.-F. Yang, "Miniature hook-shaped monopole antenna for UWB applications," Electronics Letters, vol. 46, no. 4, pp. 265-266, 2010.

[6] M. R. Ghaderi and F. Mohajeri, "A compact hexagonal wide-slot antenna with microstrip-fed monopole for UWB application," IEEE Antennas and Wireless Propagation Letters, vol. 10, pp. 682-685, 2011.

[7] R. Azim, M. T. Islam, and N. Misran, "Printed circular ring antenna for UWB application," in Proceedings of the 6th International Conference on Electrical and Computer Engineering (ICECE '10), pp. 361-363, Dhaka, Bangladesh, December 2010.

[8] S. Oudaya Coumar, R. Nakkeeran, and G. Ashwath, "Development of compact monopole antenna for UWB applications," in Proceedings of the 3rd International Conference on Computing, Communication and Networking Technologies (ICCCNT '12), Coimbatore, India, July 2012.

[9] H.-C. Tang and K.-H. Lin, "Miniaturized asymmetrical triangle UWB antenna for WUSB dongle applications," in Proceedings of the IEEE International Symposium on Antennas and Propagation and USNC/URSI National Radio Science Meeting (APSURSI '11), pp. 1467-1469, Washington, DC, USA, July 2011.

[10] R. Azim, M. T. Islam, and N. Misran, "Compact taperedshape slot antenna for UWB applications," IEEE Antennas and Wireless Propagation Letters, vol. 10, pp. 1190-1193, 2011.

[11] L. Giauffret, J.-M. Laheurte, and A. Papiernik, "Study of various shapes of the coupling slot in cpw-fed microstrip antennas," IEEE Transactions on Antennas and Propagation, vol. 45, no. 4, pp. 642-647, 1997.

[12] A. B. Constantine, Antenna Theory, Analysis and Design, John Wiley \& Sons, 3rd edition, 2005.

[13] R. Garg and P. Bhatia, Microstrip Antenna Design Handbook, Artech House, Norwood, Mass, USA, 2001.

[14] W. L. Stutzman and G. A. Thiele, Antenna Theory and Design, John Wiley \& Sons, New York, NY, USA, 2nd edition, 1998.

[15] J. Liu, S. Zhong, and K. P. Esselle, "A printed elliptical monopole antenna with modified feeding structure for bandwidth enhancement," IEEE Transactions on Antennas and Propagation, vol. 59, no. 2, pp. 667-670, 2011.

[16] M. Al-Husseini, Y. Tawk, A. El-Hajj, and K. Y. Kabalan, "A low-cost microstrip antenna for 3G/WLAN/WiMAX and UWB applications," in Proceedings of the International Conference on Advances in Computational Tools for Engineering Applications (ACTEA '09), pp. 68-70, Beirut, Lebanon, July 2009.

[17] W. Peng, W. Anguo, and D. Jiawei, "Design of the UWB antenna using fractal concept," in Proceedings of the 8th International Symposium on Antennas, Propagation and EM Theory (ISAPE '08), pp. 189-192, Kunming, China, November 2008.

[18] O. M. H. Ahmed and A. R. Sebak, "A novel maple-leaf shaped UWB antenna with a 5.0-6.0 GHz band-notch characteristics," Progress in Electromagnetics Research C, vol. 11, pp. 39-49, 2009.
[19] D. Azzeddine, N. Mourad, D. A. Tayeb, and H. M. Adnane, "Design of UWB triangular slot antenna," in Proceedings of the IEEE International Symposium on Antennas and Propagation and USNC/URSI National Radio Science Meeting (APSURSI '11), pp. 1456-1458, Spokane, Wash, USA, July 2011.

[20] M. Koohestani, M. N. Moghadasi, and B. S. Virdee, "Miniature microstrip-fed ultra-wideband printed monopole antenna with a partial ground plane structure," IET Microwaves, Antennas and Propagation, vol. 5, no. 14, pp. 1683-1689, 2011.

[21] Federal Communication Commision, FCC Report and Order on Ultra Wideband Technology, 2002.

[22] Commission of the European Communities, "Commission decision on allowing the use of the radio spectrum for equipment using ultra-wideband technology in a harmonized manner in the community," Official Journal of the European Union, vol. 50, 2007.

[23] W. Wiesbeck, G. Adamiuk, and C. Sturm, "Basic properties and design principles of UWB antennas," Proceedings of the IEEE, vol. 97, no. 2, pp. 372-385, 2009. 

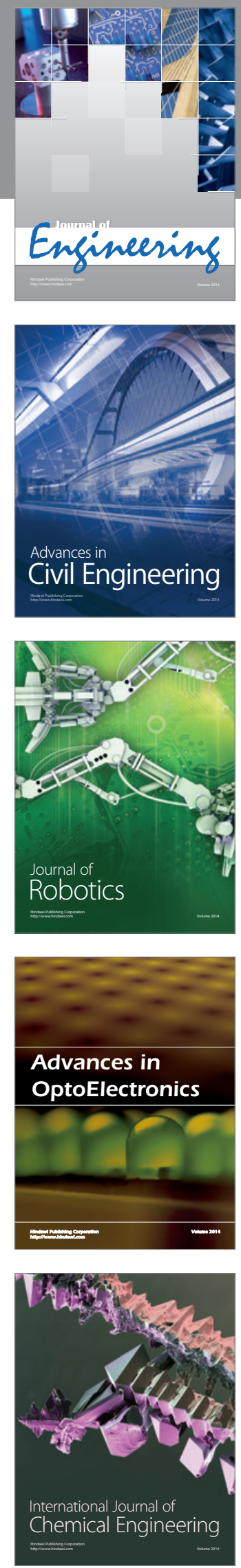

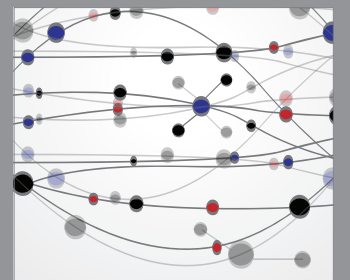

The Scientific World Journal
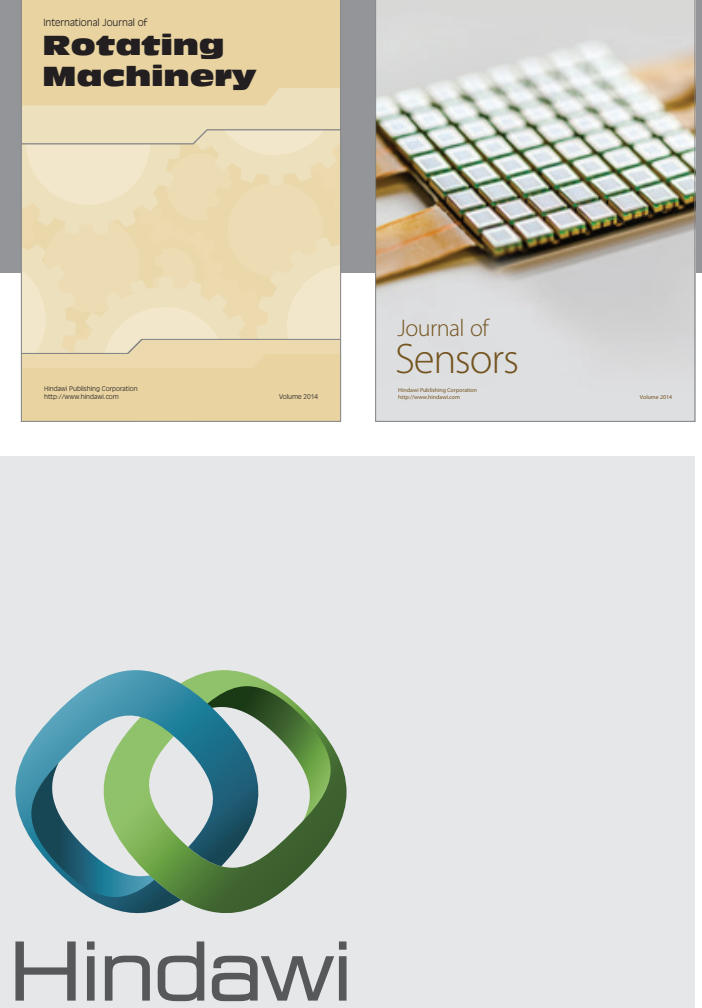

Submit your manuscripts at http://www.hindawi.com
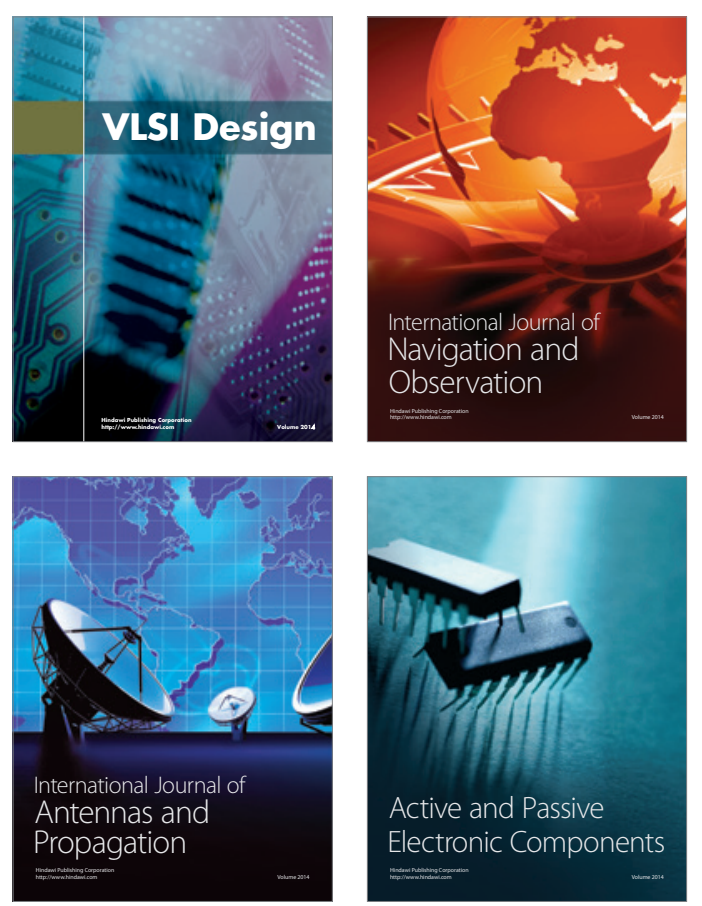
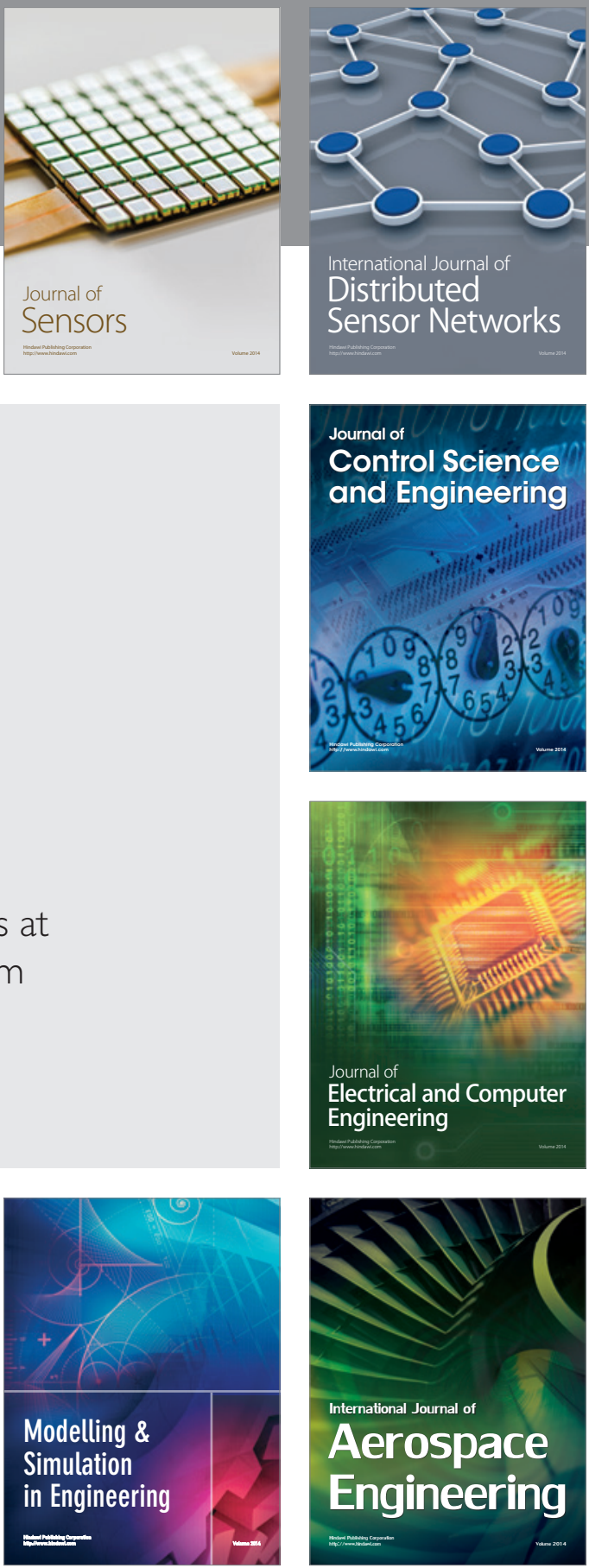

Journal of

Control Science

and Engineering
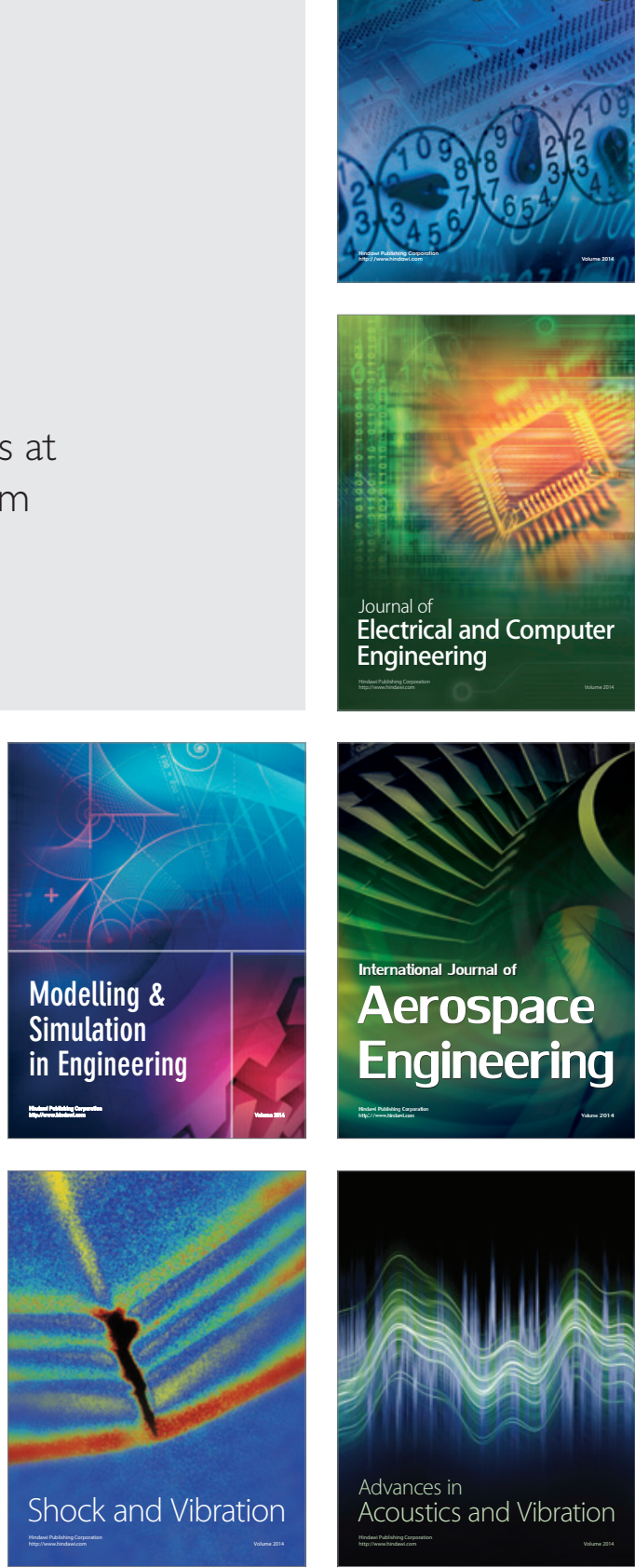